\title{
Hardness Analysis and Morphological Characterization of Copper-Zinc Alloys Produced in Pyrophosphate-Based Electrolytes
}

\author{
Lilian Ferreira de Senna*, Susana Losada Díaz, ${ }^{\text {búcio Sathler }}{ }^{\mathrm{b}}$ \\ ${ }^{a}$ Departamento de Química Analítica, \\ Universidade do Estado do Rio de Janeiro, UERJ, Instituto de Química, \\ Rua São Francisco Xavier, 524, Pavilhão Haroldo Lisboa, Sala 427, \\ 20550-013 Rio de Janeiro - RJ, Brazil \\ 'Programa de Engenharia Metalúrgica e de Materiais, COPPE/UFRJ, \\ Av. Brigadeiro Trompowski, s/n, Bl. F., Rio de Janeiro, Brazil
}

Received: October 19, 2004; Received: May 25, 2005

\begin{abstract}
In this work, copper-zinc alloy coatings on mild steel substrates were obtained in nontoxic pyrophosphatebased electrolytes, at room temperature and under continuous current. The effects of bath composition and current density on the hardness of the coatings, as well as on their morphologies, were evaluated. The results showed that the electrolyte composition, and the use of stress relieving additives strongly influence the hardness of the coatings, while the current density directly affect their morphology. Hence, for a current density of $116 \mathrm{~A} / \mathrm{m}^{2}$, copper-zinc alloy deposits with no pores or cracks were produced in a pyrophosphate-based electrolyte, especially when allyl alcohol was added to the solution.
\end{abstract}

Keywords: alloy electrodeposition, polyligand electrolytes, hardness, surface topography

\section{Introduction}

Brass electrodeposition has been widely used to modify the substrate surface in order to produce coating/substrate systems with improved properties ${ }^{1,2}$. The main applications of $\mathrm{Cu}-\mathrm{Zn}$ electrodeposition are for decorative purposes ${ }^{1-4}$, as underlayer for metallic or ceramic deposition ${ }^{5}$, for enhancement of plastic adhesion on metallic substrates $^{6}$ and for the production of shape memory alloys ${ }^{7}$. Most of the above mentioned uses were carried out by means of cyanide electrolytes. However, the disposal of the cyanide wastes and the decomposition of the bath during operation are some examples of the problems that come with the use of these baths ${ }^{8-10}$.

Searching for alternatives to conventional cyanide electrolytes, several copper-zinc stable and nontoxic solutions have been proposed ${ }^{1,9-14}$. Among them, pyrophosphate-based electrolytes emerge as a good and economic non-cyanide alternative for copper-zinc alloy electrodeposition ${ }^{10,14}$. This kind of solution presents high stability, even after continuous use, and the properties of the coatings are quite similar to those produced in cyanide baths, mainly when organic surfactants or leveling agents are used. Moreover, the wastewater treatment is less expensive than the cyanide ones ${ }^{10,15}$.

A large amount of research dealing with the effects of bath composition and deposition parameters on coating composition and decorative properties can be found in the literature ${ }^{1,13,14,16}$. Nonetheless, to the best of our knowledge, there are only few works concerning the mechanical and morphological properties of copper-zinc coatings produced in non-cyanide electrolytes ${ }^{5,6}$. Krishnan et al. ${ }^{9}$ showed that the hardness of brass coatings produced in nitriloacetic acid electrolyte depends on the current density for high concentrations of copper or zinc salts in the electrolyte. The hardest deposit (near $320 \mathrm{HV}$ ), however, was produced in the electrolyte containing the smallest concentration of copper and zinc. An improvement of hardness and mechanical properties was also achieved by producing graphite-brass composite coatings in cyanide electrolytes ${ }^{17}$.
In a previous work it was shown that high quality coatings could be produced in pyrophosphate electrolytes containing organic additives ${ }^{14}$. In this work, the influence of current density and bath composition on the hardness and morphological properties of $\mathrm{Cu}-\mathrm{Zn}$ coatings produced in such pyrophosphate-based baths was evaluated.

\section{Experimental Procedures}

\subsection{Alloy electrodeposition experiments}

$\mathrm{Cu}-\mathrm{Zn}$ alloy electrodeposition experiments were performed in the solutions shown in Table 1, at room temperature and under mechanical stirring. Plates of AISI 1008 mild steel, with an exposed area of $4.45 \times 10^{-4} \mathrm{~m}^{2}$ were used as working electrodes. Two current density values $\left(116\right.$ and $\left.153 \mathrm{~A} / \mathrm{m}^{2}\right)$ were chosen at the end of the polarization curves and were based on the chemical analysis results shown earlier ${ }^{14}$. The coatings produced in these conditions presented $\mathrm{Cu} / \mathrm{Zn}$ contents of about $80 / 20 \%$ or $70 / 30 \%$. The coatings were deposited using the same system and deposition conditions described by Senna et al. ${ }^{14}$.

\subsection{Microhardness analysis}

The microhardness of the coatings was evaluated by cross-section analysis of substrate/coating systems using a Leitz microhardness meter in the Vicker's scale. The cross-section analysis prevents multiple hardness measurements (coating + substrate), which usually occurs with a top indentation method ${ }^{18}$. The use of top indentation is only recommended for indentation depths less than $10 \%$ of the total coating thickness ${ }^{18-20}$. Three samples were collected for each measurement and the results are presented as average values \pm standard deviation. The results were compared using the independent t-test to detect any differences between the groups, with significant level $\mathrm{P}=0.05$ (Microcal Origin ${ }^{\circledR} 6.0$ ). 


\subsection{Morphological analysis}

The influence of current density and bath composition on the morphology of copper-zinc coatings was evaluated by scanning electron microscopy (SEM). The coatings were cleaned with acetone, dried in air and gold coated by vapor deposition to avoid oxidation and increase the electrical conductivity.

\section{Results and Discussion}

Coatings produced in cyanide electrolytes usually present lamellar microstructures. However, the cross section of coatings produced in

Table 1. Chemical composition of the electrolytes/mol L-1.

\begin{tabular}{cccccccc}
\hline Bath $\mathrm{CuSO}_{4}$ & $\mathrm{ZnSO}_{4}$ & $\mathrm{~K}_{4} \mathrm{P}_{2} \mathrm{O}_{7}$ & $\mathrm{KH}_{2} \mathrm{PO}_{4}$ Saccharin Butynediol & $\begin{array}{c}\text { Allyl } \\
\text { Alcohol }\end{array}$ \\
\hline 1 & 0.02 & 0.20 & 0.90 & - & - & - & - \\
2 & 0.02 & 0.20 & 0.90 & 0.07 & - & - & - \\
3 & 0.02 & 0.20 & 0.90 & 0.07 & 0.01 & - & - \\
4 & 0.02 & 0.20 & 0.90 & 0.07 & - & 0.0058 & - \\
5 & 0.02 & 0.20 & 0.90 & - & - & - & 0.07 \\
6 & 0.02 & 0.20 & 0.90 & 0.07 & - & - & 0.07
\end{tabular}

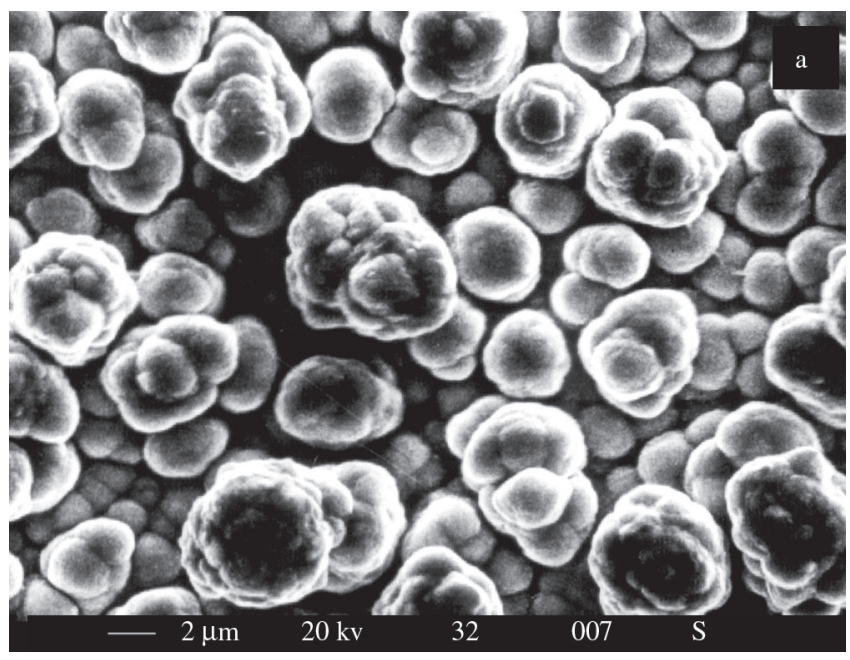

Figure 1. Morphology of coatings from Bath 1: a) $116 \mathrm{~A} / \mathrm{m}^{2}$; b) $154 \mathrm{~A} / \mathrm{m}^{2}$.
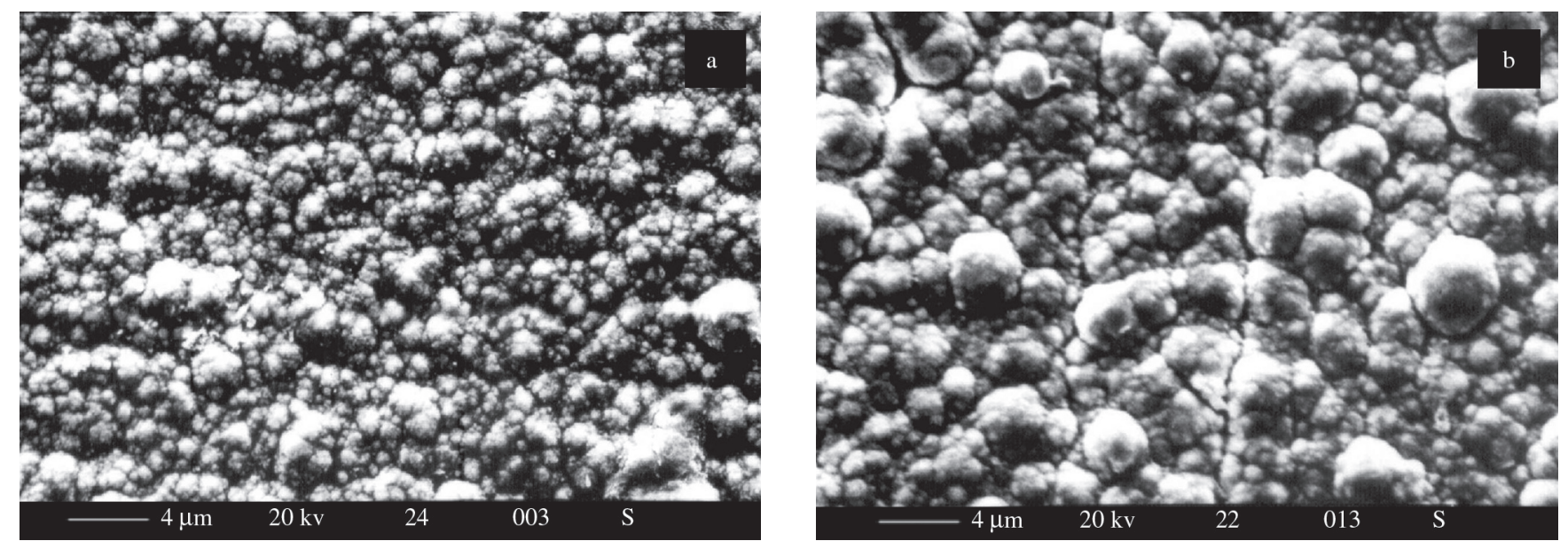

pyrophosphate-based electrolytes showed no defined microstructure $^{8}$. Therefore, only the topographies of copper-zinc coatings (average thickness $12.0 \mu \mathrm{m}$ ) produced in the electrolytes described in Table 1 were analyzed concerning their uniformity, porosity and the presence of cracks, as a function of the electrolyte composition (Figures 1 to 5).

Coatings produced in Bath 1, using current density of $116 \mathrm{~A} / \mathrm{m}^{2}$, presented a non-homogeneous surface with the presence of clusters (Figure 1a). The average grain size decreased with increasing current density, although some large clusters and small cracks could still be detected (Figure 1b). It is known that high current densities give rise to a high degree of adatoms saturation at the electrode surface ${ }^{21,22}$. This brings about the reduction in grain size observed in Figure $1 \mathrm{~b}$ if compared with Figure 1a. Moreover, coatings produced at $153 \mathrm{~A} / \mathrm{m}^{2}$ showed an increase in the amount of cracks and pores. This could be a result of the enhancement of the hydrogen reduction process that causes an increase in the interfacial $\mathrm{pH}$. It can also bring about zinc oxide and/or hydroxide incorporation into the deposit ${ }^{14,23}$. These facts account for changes in the coatings' roughness and clusters' size.

On the other hand, the coatings produced in Bath 2 at $116 \mathrm{~A} / \mathrm{m}^{2}$ consisted of a crack-free and homogeneous layer with refined grains (Figure 2a). Since the copper deposition rate was lower in this condition, if compared with Bath 1, such behavior can be attributed to the

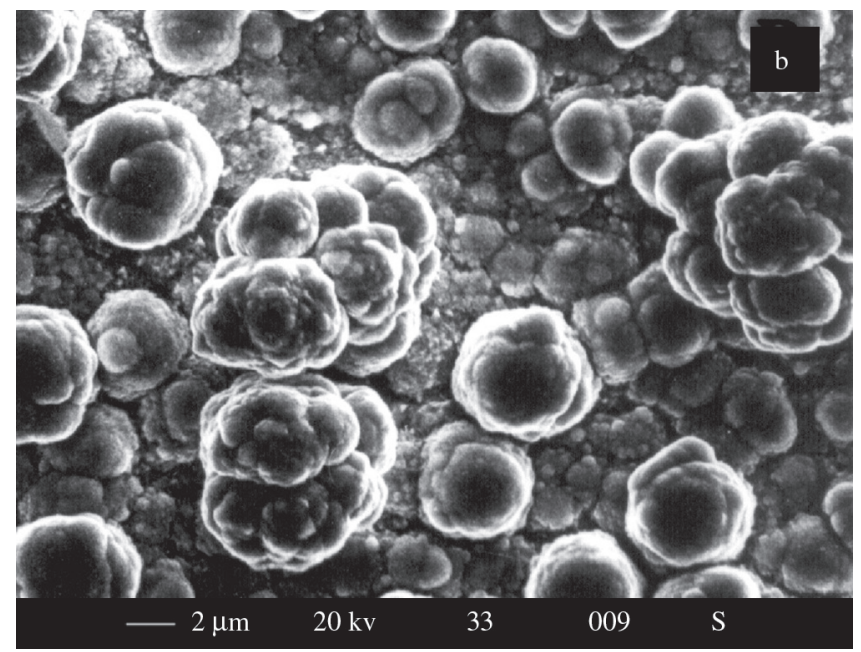

Figure 2. Morphology of coatings from Bath 2: a) $116 \mathrm{~A} / \mathrm{m}^{2}$; b) $154 \mathrm{~A} / \mathrm{m}^{2}$. 


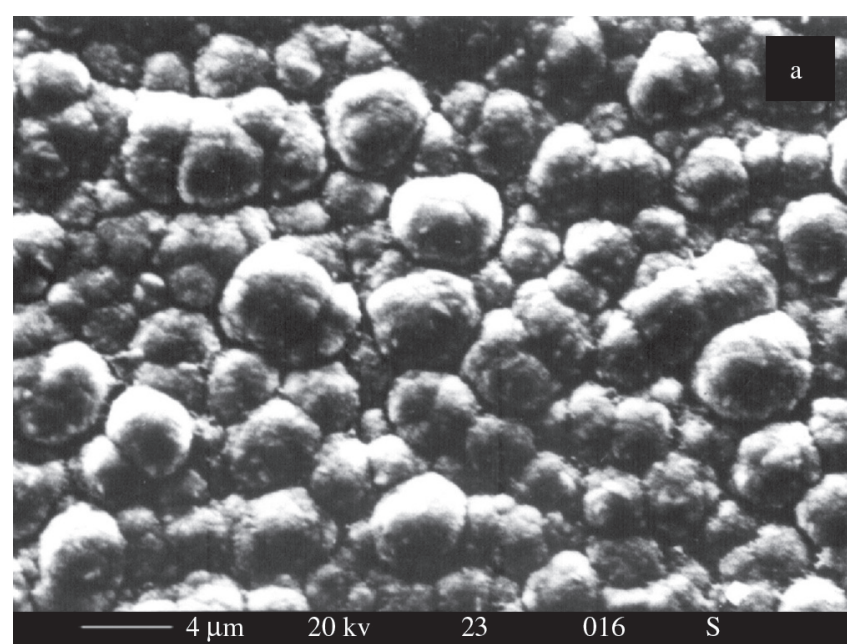

Figure 3. Morphology of coatings from Bath 3: a) $116 \mathrm{~A} / \mathrm{m}^{2}$; b) $154 \mathrm{~A} / \mathrm{m}^{2}$.

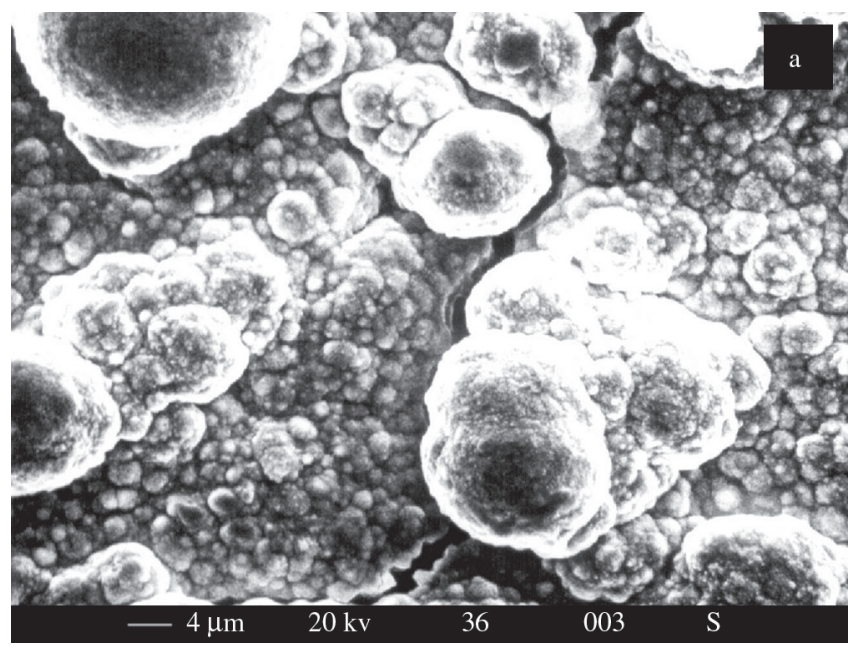

Figure 4. Morphology of coatings from Bath 4: a) $116 \mathrm{~A} / \mathrm{m}^{2}$; b) $154 \mathrm{~A} / \mathrm{m}^{2}$.

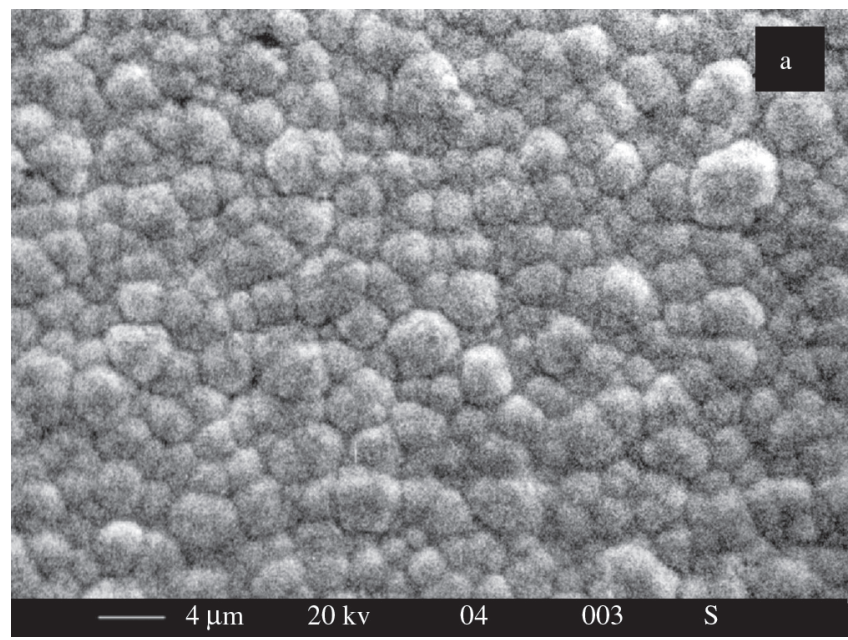

Figure 5. Morphology of coatings from Bath 5: a) $116 \mathrm{~A} / \mathrm{m}^{2}$; b) $154 \mathrm{~A} / \mathrm{m}^{2}$.

formation of a more stable copper complex in the presence of $\mathrm{H}_{2} \mathrm{PO}$ ion $^{14,24}$. The coatings produced at a higher current density $\left(153 \mathrm{~A} / \mathrm{m}^{2}\right)$ presented some clusters and small cracks (Figure $2 b$ ). Nonetheless, the
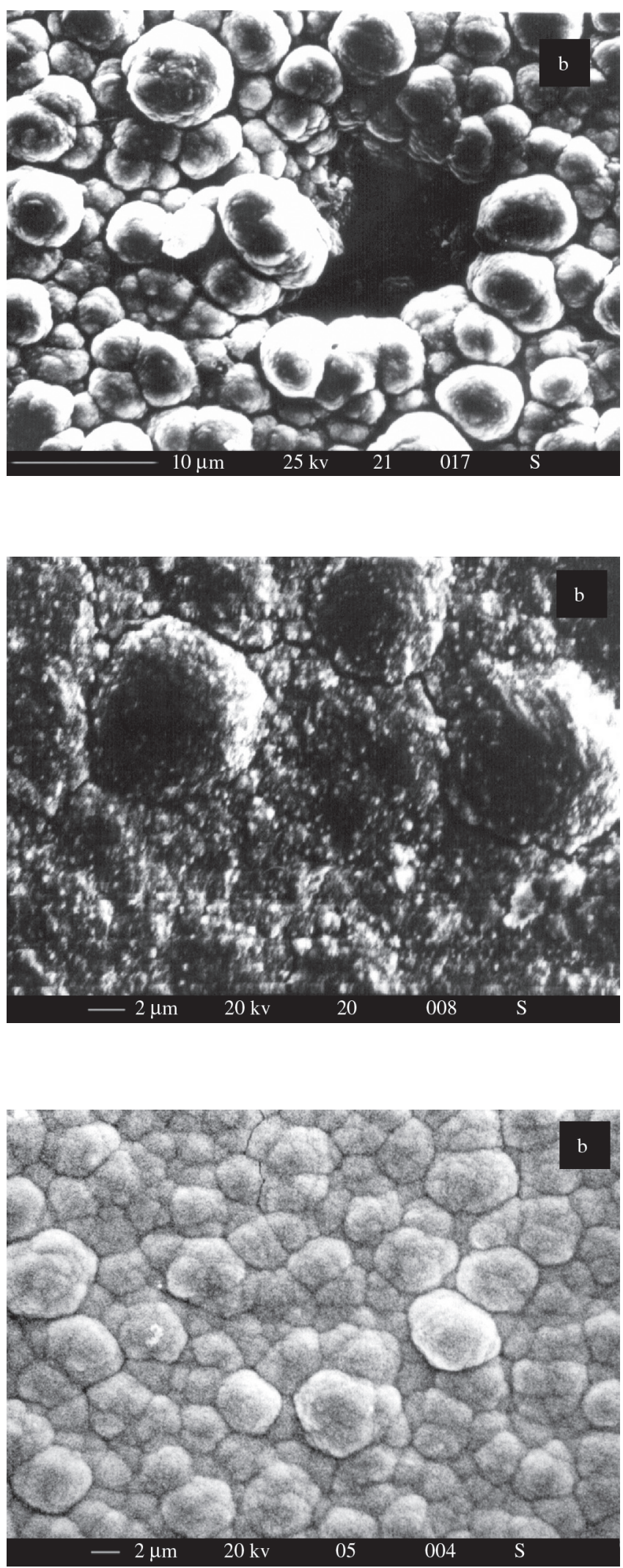

more refined microstructure and the absence of pores in the deposits obtained in Bath 2 can be a result of an additional interfacial buffering effect due to the presence of $\mathrm{H}_{2} \mathrm{PO}_{4}$ - in the solution ${ }^{14}$. 
The effect of a leveling agent addition (saccharin) to Bath 2 is shown in Figure 3. The coatings from Bath 3 were homogeneous and bright at both current density values. Larger grains can be noticed at both current densities, while high sized pores were only observed at $153 \mathrm{~A} / \mathrm{m}^{2}$ (Figure 3b). It was earlier proposed that the presence of saccharin affects the stability of copper complexes in solution, causing the increase of copper contents in the coating ${ }^{14}$. This additive also seems to affect the deposit morphology due to interfacial free energy changes that may improve grain growth. However, a more detailed study concerning the mechanism of saccharin as a leveling agent must be carried out trying to reach a final conclusion about this matter.

Small grains, large clusters and many cracks were also observed on the surface of the coatings produced with the brightening agent butynediol (Bath 4) at both current densities studied (Figure 4). These effects are similar to those described by Rogers and Taylor ${ }^{25}$ for nickel electrodeposition. They stated that butynediol is adsorbed on the surface of the electrode during the electroplating process and catalyzes the hydrogen reduction process. As a consequence, brittle and full of cracks deposits, which are not adequate to be used as underlayer to improve adhesion, are produced.

The topography of the coatings produced in the solutions containing the stress relieving agent allyl alcohol (Baths 5 and 6) was refined and compact, presenting small and homogeneous grains (Figure 5). Nevertheless, the grains increased with the current density (Figure 5b), although no cracks or porosities could be noticed in the deposits obtained at both current density values. This behavior can be attributed to the surfactant effect of allyl alcohol in the solutions ${ }^{26}$. Such additive may form a complex with the metal ions, increasing their amount in the adsorbed form at the electrode surface and thus increasing their reduction rate (induced adsorption) ${ }^{22}$. In addition, its stress relieving properties may also prevent coating embrittlement caused by the simultaneous hydrogen evolution.

The relationship between microhardness of the deposits produced at the electrolytes described in Table 1, and the deposition current density is presented in Figure 6a. Comparing the microhardness of coatings produced at a given bath in the two different current density values, no significant differences could be observed $(\mathrm{P}>0.05)$ for all baths studied. Analogous results were obtained by Krishnan et al. ${ }^{9}$, who produced brass coatings in a solution containing nitriloacetic acid (NTA) as a complexing agent and used similar copper and zinc concentrations as those employed in the present work. However, it is important to note that among all baths studied, coatings produced in baths 1 and 4 (Table 1) presented the highest microhardness values.

Comparing the zinc content in coatings produced from each bath in Table 1 , there was a significant increase $(\mathrm{P}<0.05)$ of this variable with the current density for all baths studied (Figure $6 \mathrm{~b}$ ). Despite the comparable values of copper and zinc ionic radii, one should consider that a higher number of zinc atoms in the lattice of the alloy would cause an increase in the lattice distortion, as expected for copper-based alloys produced at high overpotential values ${ }^{2}$. This would result in an increase of the microhardness, as it is commonly observed for $\mathrm{Cu}-\mathrm{Zn}$ alloy coatings with high $\mathrm{Zn}$ contents obtained in cyanide baths ${ }^{2,27}$. However, such dependence of hardness on the alloy composition was not obvious for coatings obtained in pyrophosphatebased solutions (Figure 6a).

It is important to point out that most of the electrolytically obtained alloys, produced from different baths, usually consist of fine crystals, non-uniform in composition and characterized by a considerable distortion of the crystal lattice, originated during the formation of the non-equilibrium phases at the cathode, which occurs at high overpotential values. As a result, it is normally difficult to analyze these alloy deposits by $\mathrm{x}$-rays examination and, in some cases,

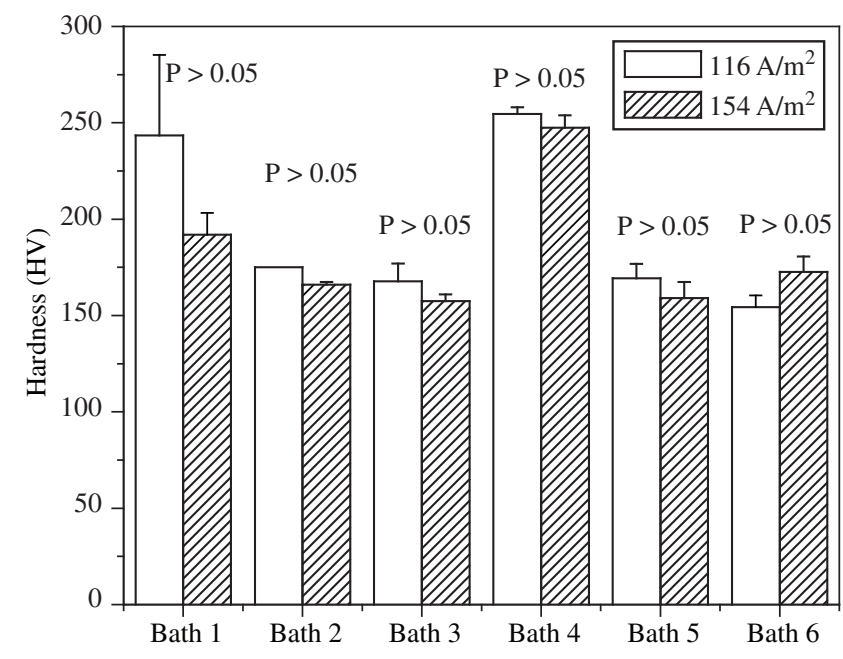

(a)

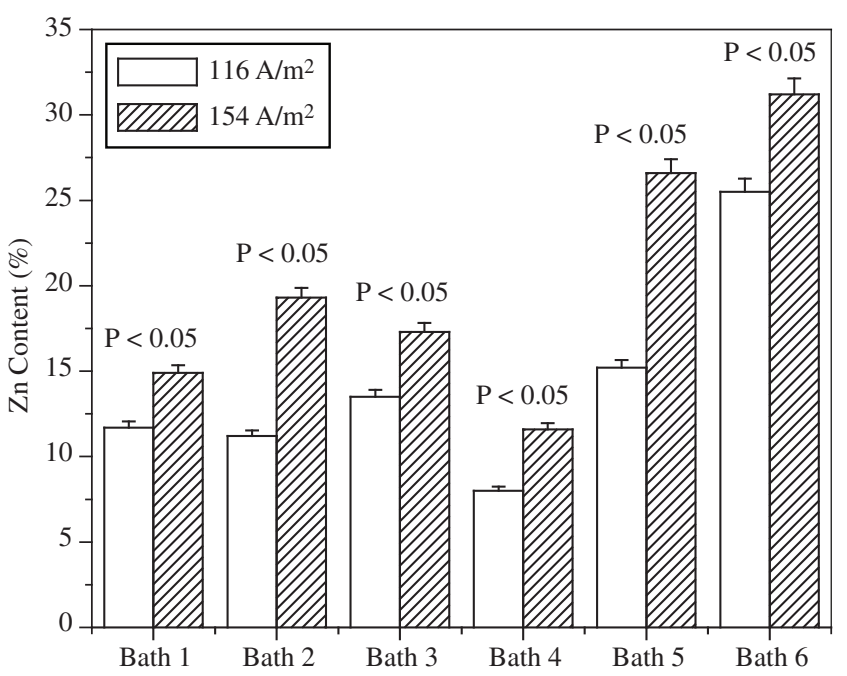

(b)

Figure 6. a) Hardness; b) Zinc content (atomic \%) of the coatings from Baths 1 to 6 , produced in the two current density values: $116 \mathrm{~A} / \mathrm{m}^{2}$ and $154 \mathrm{~A} / \mathrm{m}^{2}$.

phases present in a given deposit can be only partially revealed ${ }^{2}$. In the present work, all coatings were obtained at high current density values and, consequently, at high overpotentials. In this case, lattice distortion could be related to the production of non-equilibrium phases at high overpotential values. Lattice distortion can be responsible for non-homogeneous microscopic residual stress and can significantly contribute to the coating microhardness. Moreover, all coatings were produced at room temperature and the thermal mismatch could also contribute to macroscopic residual stress as well as to the microhardness values of the electrodeposited layers ${ }^{28}$.

In the kind of solution studied in this work, the chemical composition of the electrolytes seems to be the more significant factor affecting the hardness of the coatings. As observed in Figure 6a, the highest microhardness values were obtained for coatings produced in Bath 4, containing butynediol. As already mentioned, this compound favors hydrogen evolution, giving rise to hard and brittle deposits. Statistically, coatings produced in Bath 1 presented comparable 
microhardness values $(\mathrm{P}>0.05)$. It was an expected result due to the poor buffering action of the pyrophosphate solution ${ }^{14,23}$. It is interesting to note, however, that coatings produced at $116 \mathrm{~A} / \mathrm{m}^{2}$ presented an average microhardness value higher than those obtained at $154 \mathrm{~A} . \mathrm{m}^{-2}$. Moreover, the amount of cracks in the coatings from Bath 1 was smaller than in those produced in Bath 4.

Microhardness values of the coatings produced in Baths 2, 3, 5 and 6 were quite similar and smaller than the others mentioned before. In Bath 2 the buffering effect of $\mathrm{H}_{2} \mathrm{PO}_{4}^{-}$should prevent the interface alkalination $^{14,23}$, resulting in deposits with low microhardness. It was shown earlier that saccharin decreases the copper-pyrophosphate complex stability, giving rise to copper rich alloys ${ }^{14}$. On the contrary, allyl alcohol increases the stability of this complex, allowing the increase of zinc content in the alloy deposit. However, it is important to remark that both saccharin and allyl alcohol are stress relieving and leveling agents. For this reason, one should expect a decrease in the mismatch between coating and substrate surfaces, which would reduce the residual stress and the hardness values. Such behavior could explain the smaller microhardness values obtained for the coatings produced in baths 3, 5 and 6 (Figure 6a).

\section{Conclusions}

The morphology, roughness and microhardness of $\mathrm{Cu}-\mathrm{Zn}$ alloy deposits obtained by electrodeposition in pyrophosphate-based electrolytes depended on both the current density and the electrolyte composition. In general, the increase in the current density led to the production of non-homogeneous coatings with larger amount of defects and higher roughness. However, coatings produced in the electrolytes containing allyl alcohol (Baths 5 and 6) were pore and crack-free even for the highest value of current density studied. This behavior can be attributed to the stress relieving characteristics of this substance. The cracks observed on the surface of coatings produced in Bath 4 could be related to the catalyst effect of butynediol on hydrogen evolution.

There was no apparent relationship between zinc content in the coatings and their microhardness. Moreover, the electrolyte composition seems to affect more intensively the microhardness of the deposits than the current density. The catalyst effect of butynediol on hydrogen evolution produced brittle coatings, which are not appropriate to support mechanical load or other upper coatings. On the other hand, coatings produced in baths containing allyl alcohol and saccharin presented smaller hardness values due to their stress relieving action. The buffering effect of $\mathrm{H}_{2} \mathrm{PO}_{4}^{-}$may also help to prevent local $\mathrm{pH}$ changes, giving rise to deposits with low microhardness values, if compared to the ones obtained in the absence of this compound.

\section{References}

1. Vagramyan TA, Slov'eva ZA. Technology of electrodeposition. Teddington, England: Robert Draper Ltd; 1961.

2. Vagramyan TA. In: Kruglikov SS. editor. Electrochemistry. Jerusalem: Israel Program of Scientific Translation Ltd.; 1970.

3. Lainer VI. Modern electroplating. Jerusalem: Israel Program of Scientific Translation Ltd; 1970.

4. Fujiwara Y, Enomoto H. Electrodeposition of $\beta$ '-brass from cyanide baths with accumulative underpotential deposition of $\mathrm{Zn}$. Journal of the Electrochemical Society. 2000; 147(5):1840-1846.

5. Harris AW. U. S. Patent no. 2,546. 1951; 447.

6. Ambrosio L, Fillipo D. Processing and investigation of production of steel brass-coated cords for radial tires (I): electrolytes. Protection of Metals. 1986; 22(1):66-71.
7. Page D, Roy S. Electrodeposition of thin filmf Cu- $\mathrm{Zn}$ shape memory alloys. Journal of Phyics IV. 1997; 5(7):269-274.

8. Senna LF. Estudo de parâmetros para eletrodeposição de ligas cobre/ zinco em eletrólitos de pirofosfato. [M.Sc. thesis]. Rio de Janeiro: Federal University of Rio de Janeiro, Brazil; 1991.

9. Krishnan RM, Muralidharan VS, Natarajan SR. A non-cyanide brass plating brath. Bulletin of Electrochemistry. 1996; 12(5-6):274-277.

10. Johansen KD, Page Roy S. A systematic investigation of current efficiency during brass deposition from a pyrophosphate electrolyte using RDE, RCE, and QCM. Electochimica Acta. 2000; 45(22-23):3691-3702.

11. Kovaleva, OI. Electrodeposition of a copper/zinc alloy from 1,2-diaminopropane electrolyte. Soviet Electrochemistry. 1982; 18(4):509-511.

12. Galinker VS. Conditions for the electrodeposition of a copper/zinc alloy from tripolyphosphate electrolyte. Protection of Metals. 1971; $7(2): 210-212$.

13. Fujiwara $Y$, Enomoto H. Electrodeposition of $\mathrm{Cu} / \mathrm{Zn}$ alloys from glucoheptanate baths. Surface Coating and Technology. 1988; 35(1-2):101-11.

14. Senna LF, Díaz SL, Sathler L. Electrodeposition of copper-zinc alloys in pyrophosphate-based electrolytes. Journal of Applied Electrochemistry. 2003; 33(12):1155-1161.

15. Johannsen K. Effect of temperature \& bulk stirring on electroplating of brass from pyrophosphate electrolyte. Plating and Surface Finishing. 2001; 88(6):104-108.

16. Kostrova GF, Obozinkaya VA. Optimum conditions for electroplating decorative brass from pyrophosphate baths. Soviet Electrochemistry. 1985; 21(3):352-354.

17. Ghorbani M, Mazaheri M, Khangholi K, Kharazi Y. Electrodeposition of graphite-brass composite coatings and characterization of the tribological properties. Surface and Coating Technology. 2001; 148(1):71-76.

18. Senna LF. Produção e caracterização de filmes duros de carbonitreto de titânio $(T i C, N)$. [D.Sc. thesis], Rio de Janeiro, Brazil: Federal University of Rio de Janeiro; 1998.

19. Senna LF, Achete CA, Hirsch T, Freire Jr, FL. Structural, chemical, mechanical and corrosion resistance characterization of TiCN coatings prepared by magnetron sputtering. Surface and Coating Technology. 1997; 94-95:390-396.

20. Berlind T, Hellgren N, Johansson MP, Hultman L. Microstructure, mechanical properties and wetting behavior of Si-C-N thin films grown by reactive magnetron sputtering. Surface and Coating Technology. 2001; 141(2-3):145-155.

21. Despi AR. In: Conway, BE, Bockris, JOM, Yeager, E, Khan, SUM, White RE, editors. Comprehensive Treatise of Electrochemistry (vol. 7). New York: Plenum; 1983.

22. Onciu L, Muresan L. Some fundamental aspects of leveling and brightening in metal electrodeposition. Journal of Applied Electrochemistry. 1991; 21(7):565-574.

23. Ishikawa M, Enomoto H, Matsuoka M, Iwakura C. Effect of tetraborate ions on electrodeposition of nickel-copper alloy from a pyrophospahte bath. Electrochimica Acta. 1994; 39(14):2153-2157.

24. Orekhova VV, Adryushchenko FK. Investigation of the kinetics of electrode reactions in polyligand electrolytes. Soviet Electrochemistry. 1978; 14(2):240-245.

25. Rogers GT, Taylor, KJ. The reactions of coumarin, cinnamyl alcohol, butynediol and propargil alcohol at electrode on which nickel is depositing. Electrochimica Acta. 1966; 11(12):1685-1697.

26. Mumladze YaV. Role of certain surfactants in brass electrodeposition from pyrophosphate bath. Soviet Electrochemistry. 1988; 24(6):828-830.

27. Díaz SL. Eletrodeposição de ligas cobre/zinco. [Unpublished COPPETEC Project No. PP-3414]. Rio de Janeiro: Federal University of Rio de Janeiro; 1988.

28. Senna LF, Achete CA, Mattos OR, Hirsch T. Characterization of PVDTiCN layers by physical and electrochemical methods. Surface Engineering. 2005 (in press). 